\title{
Coralan Experience (CORE) Survey - First Malaysian Experience of Ivabradine in Stable Angina
}

Gim-Hooi Choo ${ }^{*}$, Ahmad Nizar Jamaluddin', David Kwang-Leng Quek² and Tan Beng Hong

${ }^{1}$ Sime Darby Medical Centre Subang Jaya, 1, Jln SS12/1, 47500, Subang Jaya, Selangor, Malaysia

${ }^{2}$ Pantai Medical Centre Bangsar, 8, Jalan Bukit Pantai, 59100 Kuala Lumpur, Malaysia

\begin{abstract}
Aims: This non-randomised observational study primarily sought to evaluate the initial experiences with Ivabradine in these patients in terms of its efficacy in angina-related endpoints as well as highlighting safety issues, if any.

This study also describes the profile of patients with stable angina pectoris.

Methodology: Patients with angina pectoris and baseline HR above $70 \mathrm{bpm}$ were recruited. Ivabradine $5 \mathrm{mg}$ bd was added to baseline treatment, and further dose increment to $7.5 \mathrm{mg}$ bd after 1 month if the HR remains above $70 \mathrm{bpm}$. Follow-up assessments were made at 2 time-points after initial recruitments i.e. after 1 and 2 months. Haemodynamic effects on blood pressure and HR were measured. Angina related parameters were assessed via patient interview. Safety issues were also reported.

Results: 304 patients were recruited. There is a high prevalence of underlying hypertension $(65.1 \%)$ and diabetes mellitus (46.4\%). More than half (53.3) of the patients were already on baseline beta-blocker therapy. As expected, ivabradine use resulted in the significant reduction in HR from $81.7 \pm 13.8 \mathrm{bpm}$ to $67.0 \pm 8.9 \mathrm{bpm}$ without significant change in the BP measurements. All angina severity indicators e.g. number of angina episodes, use of short-acting nitrates and angina class improved. Side-effects were uncommon. This treatment was well tolerated and accepted by most patients.

Conclusion: Ivabradine as a pure HR-reduction agent is an efficacious strategy for angina improvement with minimal concerns of safety and side-effects. This early experience of Ivabradine use and its effects in Malaysia was in concordance with currently available clinical evidence.
\end{abstract}

Keywords: Stable angina pectoris; Ivabradine; Heart rate; $\mathrm{I}_{\mathrm{f}}$ inhibition

\section{Introduction}

Stable angina pectoris is induced or aggravated when increased heart rate (HR) shifts the balance towards an oxygen deficit in the equilibrium between myocardial oxygen demand $v$ s. supply.

Annual incidence of angina is as high as 213 per 100,000 population in those above the age of 30 [1]. Despite its high prevalence, investigational data on stable coronary artery disease especially those with manifest angina is scarce. Local data on prevalence of stable angina pectoris is not available. Nevertheless, cardiovascular disease death is the most common cause of mortality in Ministry of Health hospitals in Malaysia [2].

This study evaluates the early experiences with Ivabradine in Malaysia amongst physicians in the management of stable angina pectoris.

Ivabradine is a novel, first its kind agent that targets the $\mathrm{I}_{\mathrm{f}}$ - channel. This channel is almost exclusively found in the SA node [3]. Ivabradine selectively reduces HR (negative chronotropic effect) via its action on the SA node without significant adverse inotropic effects on the myocardium [4]. It has been shown to improve ischaemic thresholds, reduce anginal events and severity and also reduce ischaemic events in patients with stable coronary artery disease (CAD) [5-11].

\section{Method}

In the 4-month period between November 2008 and February 2009, a survey was initiated to assess the anti-anginal effects of Ivabradine.
Stable angina patients were recruited by 73 participating clinicians based on the following inclusion criterias:

- Symptomatic CAD with resting HR 60 bpm and above

- Age 18 and above

Following the recruitment visit, patients were assessed in 2 further monthly study visits, i.e. Total of 3 clinic reviews at 0,1 and 2 months.

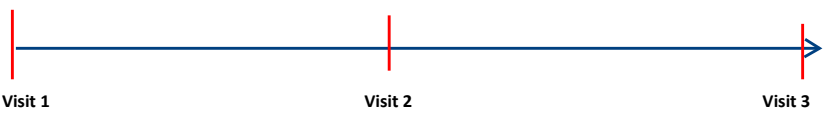

In addition to baseline demographic data, concomitant comorbidities were noted. Background pharmacological treatment classes - antiplatelets, anti-ischaemic therapies, lipid lowering agents, ACE-inhibitors, etc. (without dosages) were recorded.

*Corresponding author: Gim-Hooi Choo, Sime Darby Medical Centre Subang Jaya, 1, JIn SS12/1, 47500 Subang Jaya, Selangor, Malaysia, E-mail: ghchoo@yahoo.com

Received January 18, 2013; Accepted January 23, 2013; Published January 25, 2013

Citation: Choo GH, Jamaluddin AN, Quek DKL, Hong TB (2013) Coralan Experience (CORE) Survey - First Malaysian Experience of Ivabradine in Stable Angina. Pharmaceut Anal Acta 4: 213. doi:10.4172/2153-2435.1000213

Copyright: $\odot 2013 \mathrm{Choo} \mathrm{GH}$, et al. This is an open-access article distributed under the terms of the Creative Commons Attribution License, which permits unrestricted use, distribution, and reproduction in any medium, provided the original author and source are credited. 
Citation: Choo GH, Jamaluddin AN, Quek DKL, Hong TB (2013) Coralan Experience (CORE) Survey - First Malaysian Experience of Ivabradine in Stable Angina. Pharmaceut Anal Acta 4: 213. doi:10.4172/2153-2435.1000213

Page 2 of 4

$\mathrm{BP}$ and HR measurements were specified as the average of 2 readings taken after a period of rest for at least 5 minutes.

Following recruitment, Ivabradine $5 \mathrm{mg}$ bid was prescribed at the initial visit and the dose up-titrated to $7.5 \mathrm{mg}$ bid if the HR remained above $60 \mathrm{bpm}$ at the $2^{\text {nd }}$ Clinic visit.

The primary endpoints of this study were the angina-related parameters i.e. number of angina episodes per week, frequency of short-acting nitroglycerin use and severity of reported angina based on Canadian Cardiovascular Society (CCS) Grading [12].

Subjective patient assessment of efficacy of newly introduced agent, Ivabradine were recorded at visits 2 and 3. Patients were asked the following questions:

- How do you feel after getting Ivabradine prescription? options: better, the same or worse

- How would you rate the efficacy of Ivabradine compared to existing therapies in improving your angina symptoms. Options: better, the same or worse

Patient reported side-effects, withdrawal rates and reasons were also recorded.

\section{Statistical methods}

Descriptive statistics were presented for continuous variables (means $\pm[\mathrm{SD}])$ and categorical variables $(\mathrm{n}[\%])$.

Comparisons of continuous variables were made using the Student's t-test. Level of significance was $5 \%$.

The CCS classification for angina severity was an ordinal categorical variable, but is coded as a quantitative variable to allow a numerical representation of its severity grade.

\section{Results}

\section{Baseline characteristics}

A total of 304 patients were recruited. At the end of 2 months, 213 patients completed the 2 follow-up visits (30\% drop-out rate).

The mean age of the patients was $63.3 \pm 12.9$ years. The cohort was predominantly male $(64 \%)$.

The mean systolic BP was $132 \pm 17 \mathrm{mmHg}$ and diastolic BP was 80 $\pm 9 \mathrm{mmHg}$.

The mean baseline HR was $82 \pm 14 \mathrm{bpm}$ (range 60-150 bpm).

\section{Co-morbid conditions}

65.1\% ( $\mathrm{n}=198)$ patients were hypertensives and diabetes mellitus was present in nearly half $(46.4 \%[\mathrm{n}=141])$ of the cohort. Heart failure was present in $28.6 \%(\mathrm{n}=87)$ and bronchial asthma in 33 patients $(10.9 \%)$.

Concomitant other non-cardiac atherosclerotic disease was manifested in 38 patients [15 patients (4.9\%) with previous cerebrovascular events and $23(7.6 \%)$ with peripheral vascular disease]. 20 patients $(6.6 \%)$ had chronic kidney disease. Erectile dysfunction was reported in 15 patients $(4.9 \%)$ (Table 1$)$.

\section{Baseline therapies}

Majority of these patients with angina pectoris were on standard of care therapy with anti-platelet and lipid lowering agents. About $60 \%$ of them were on a renin-angiotensin system blocker (equally distributed between ACE-inhibitors and angiotensin receptor blockers). About a third was already on therapies for symptom-relief with either nitrates, calcium-channel blockers or metabolic agents - either singly or in combinations (Table 1).

\section{Baseline angina status}

Almost half of the cohort $(\mathrm{n}=148(48 \%))$ experienced Class II angina. Almost equal number of patients were in angina CCS Class I $[n=69(23 \%)]$ and Class III [ $n=66(22 \%)]$. The remaining 21 patients (7\%) were in the most severe angina category Class IV (Table 2).

\section{Treatment effects}

The mean baseline HR was $81.7 \pm 14.3 \mathrm{bpm}(60-150 \mathrm{bpm})$. After 1 month, the mean HR was reduced to $70.3 \pm 10.4 \mathrm{bpm}(48-120 \mathrm{bpm})$ and at the end of study, mean HR was $67.0 \pm 8.9 \mathrm{bpm}(49-109 \mathrm{bpm})$ (Figures 1, 2 and Table 3).

Ivabradine treatment produced no significant alteration of the systolic blood pressure. The diastolic blood pressure however was reduced significantly on follow-up.

All the indices of angina status improved with the introduction of ivabradine.

\begin{tabular}{|c|c|c|}
\hline Therapy & Number & (\%) \\
\hline Anti-platelet & 267 & 87.8 \\
\hline Lipid lowering & 252 & 82.9 \\
\hline Beta-blockers & 168 & 53.3 \\
\hline ACE-inhibitors & 94 & 30.9 \\
\hline *ARBs & 94 & 30.9 \\
\hline Calcium-channel blockers & 103 & 33.9 \\
\hline Long-acting nitrates & 116 & 38.2 \\
\hline Trimetazidine & 109 & 35.9 \\
\hline
\end{tabular}

*ARB=Angiotensin receptor blocker

Table 1: Baseline pharmacotherapies.

\begin{tabular}{|c|c|c|c|c|}
\hline Angina & Mean & SD & Minimum & Maximum \\
\hline CCS Class & 2.13 & 0.84 & 1 & 4 \\
\hline No of episodes/wk & 3.58 & 3.45 & 0 & 20 \\
\hline No of NTG usage/wk & 2.22 & 3.53 & 0 & 30 \\
\hline
\end{tabular}

Table 2: Baseline angina-related parameters.

\section{Heart rate}

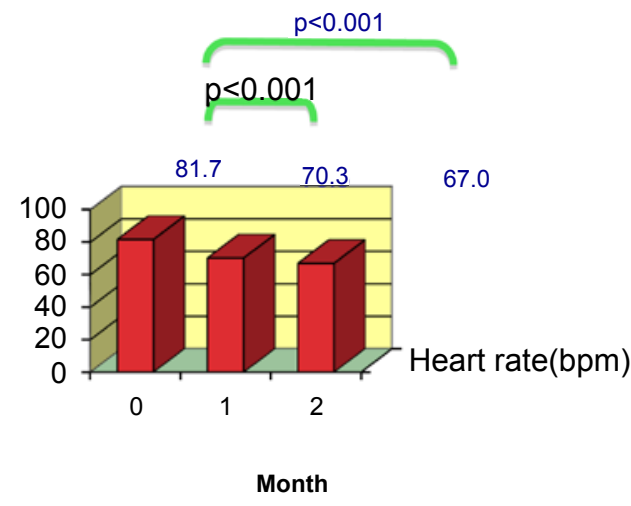

Figure 1: Heart rate changes during follow-up. 
Citation: Choo GH, Jamaluddin AN, Quek DKL, Hong TB (2013) Coralan Experience (CORE) Survey - First Malaysian Experience of Ivabradine in Stable Angina. Pharmaceut Anal Acta 4: 213. doi:10.4172/2153-2435.1000213

Page 3 of 4

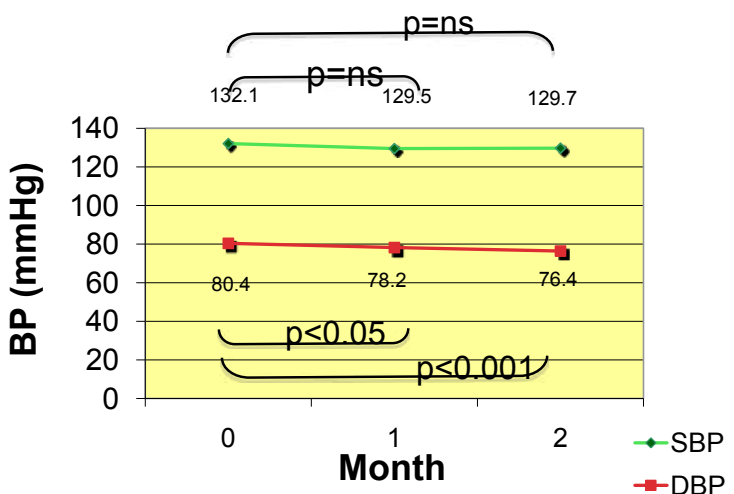

Figure 2: Blood Pressure changes on follow-up.

\begin{tabular}{|c|c|c|c|}
\hline & Visit 1 & Visit 2 & Visit 3 \\
\hline SBP $(\mathrm{mmHg})$ & $132.1 \pm 16.8$ & $129.5 \pm 15.7$ & $129.7 \pm 15.1$ \\
\hline $\mathrm{DBP}(\mathrm{mmHg})$ & $80.4 \pm 8.7$ & $78.2 \pm 8.6^{*}$ & $76.4 \pm 7.9^{*}$ \\
\hline HR $(\mathrm{bpm})$ & $81.7 \pm 13.8$ & $70.3 \pm 10.3^{*}$ & $67.0 \pm 8.9^{*}$ \\
\hline Range of HR(bpm) & $60-150$ & $48-120^{*}$ & $49-109^{*}$ \\
\hline
\end{tabular}

${ }^{*} \mathrm{p}<0.001$

Table 3: Treatment effects on HR and BP during follow-up.

\section{Angina grade (CCS classification) changes}

At study initiation about half of the patients (132 (48.7\%)), were in class II angina (Figure 3). During follow-up, progressively greater proportion of patients improved in their angina status. By the last visit, half of the cohorts were in angina class I. There was a paradoxical increase in the number of patients who experienced class III angina after the first visit but this reduced remarkably to just $7.6 \%$ by the second month of follow-up.

Not only were the angina grades improved, the frequency of angina episodes and concomitant use of short acting nitrates were also less frequent. These improvements were seen within a month of initiating Ivabradine $5 \mathrm{mg}$ bid. Escalation of dosage to $7.5 \mathrm{mg}$ bid provided for a non-significant trend towards further improvements in angina-related parameters (Tables 4 and 5).

\section{Patient-reported assessment of treatment effects}

Majority of patients reported better sense of well-being after the prescription of ivabradine and had favourable perception of the efficacy of ivabradine in the control of angina compared to baseline therapies. This rough measure of improvement in patient's quality of life and satisfaction with the newly added therapy improved over the 2-month follow-up. Very few actually felt worse or had negative perception of the new treatment (Table 6).

\section{Side-effects}

In general, side-effects were few (23 reported events) and uncommon. General discomfort, being unwell and headache was reported in 6 patients. There were 4 reports of chest discomfort in association with shortness of breath, nausea and giddiness. Bradycardia with hypotension was encountered in 2 patients. Another 2 had decompensated heart failure with bradycardia. Complaints of leg swelling with numbness, lethargy were seen in 2 cases for each complaint. Single reports of phosphene phenomenon, asthma attack, dyspnoea, pruritic rash and dyspepsia were documented.
2 deaths were reported during follow-up.

Patient 1, was a 70 year old male patient with multiple comorbidities (hypertension, type $2 \mathrm{DM}$ and heart failure) and Class IV angina. He had 7 reported angina episodes/week.

Patient 2, was an 80 year old lady with Class II angina and type 2 DM. She had 3 angina attacks weekly.

Causes of death were unknown.

7 patients underwent coronary revascularisation during the followup period.

\section{Conclusion}

Ivabradine reduced HR significantly in patients with stable angina pectoris. All measures of angina severity - angina class, frequency of angina episodes and the need for short-acting nitrates improved after ivabradine addition to existing anti-ischaemic and anti-anginal therapies. Adverse drug reactions were uncommon and this agent was well tolerated and accepted by patients.

This study of early experience with ivabradine use in Malaysia showed efficacy and safety profile which was consistent with currently available evidence in other largely Caucasian populations.

\section{Limitations}

This was a small observational study. Inherent bias in such trial

$$
\begin{aligned}
& \text { Distribution of Angina Class } \\
& \text { (CCS) at 1 1st. Visit } \% \text { ) }
\end{aligned}
$$
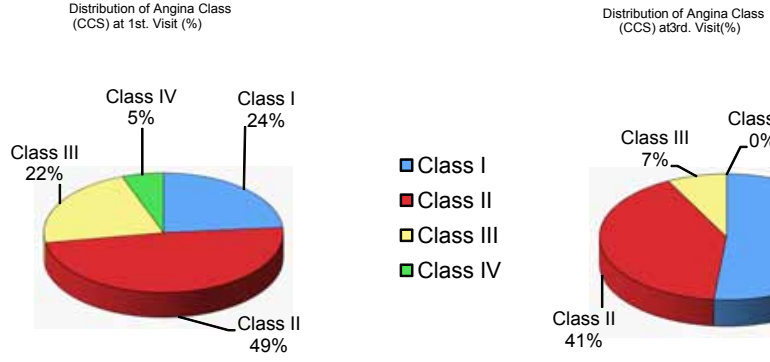

$\square$ Class I

口Class II

口Class III

口Class IV

Figure 3: Angina Class Differences at baseline visit and at end of study.

\begin{tabular}{|l|c|c|c|}
\hline & Visit 1 & Visit 2 & Visit 3 \\
\hline CCS Class & $2.1 \pm 0.8$ & $1.7 \pm 0.7^{*}$ & $1.6 \pm 0.6^{* *}$ \\
\hline No of Episodes/week & $3.6 \pm 3.5$ & $1.9 \pm 2.6^{*}$ & $1.5 \pm 2.3^{* *}$ \\
\hline Median no of episodes/week & 3 & 1 & 1 \\
\hline No of NTG usage/week & $2.2 \pm 3.0$ & $1.1 \pm 2.3^{*}$ & $0.8 \pm 1.9^{* *}$ \\
\hline
\end{tabular}

Comparisons between Visit 1 \& Visit 2 were significant with $p<0.05$

" Comparisons between Visit 2 \& Visit 3 did not meet statistical significance ( $p=n s$ )

Table 4: Angina status during follow-up.

\begin{tabular}{|c|c|c|c|c|}
\hline Angina Class & Class I & Class II & Class III & Class IV \\
\hline Visit 1 & $64(23.6 \%)$ & $132(48.7 \%)$ & $60(22.1 \%)$ & $15(5.6 \%)$ \\
\hline Visit 2 & $121(44.6 \%)$ & $21(7.8 \%)$ & $127(46.9 \%)$ & $2(0.7 \%)$ \\
\hline Visit 3 & $115(51.6 \%)$ & $91(40.8 \%)$ & $17(7.6 \%)$ & $0(0 \%)$ \\
\hline
\end{tabular}

Table 5: Angina CCS grades during follow-up.

\begin{tabular}{|c|c|c|c|}
\hline & Better & The same & Worse \\
\hline Wellness (Visit 2) & $202(75.0 \%)$ & $59(21.9 \%)$ & $8(3 \%)$ \\
\hline Wellness (Visit 3) & $174(82.5 \%)$ & $37(17.5 \%)$ & $2(0 \%)$ \\
\hline Efficacy (Visit 2) & $163(62.7 \%)$ & $89(34.2 \%)$ & $8(3.1 \%)$ \\
\hline Efficacy (Visit 3) & $158(75.6 \%)$ & $51(24.4 \%)$ & $0(0 \%)$ \\
\hline
\end{tabular}

Table 6: Patient reported efficacy and wellness measures. 
design and small cohort need to be taken into account in the data interpretation.

\section{Discussion}

This paper was a non-randomised observational study evaluating the early experiences with Ivabradine in the management of stable angina pectoris.

This small study highlighted an increasingly recognized fact that these symptomatic patients were not well treated to lower targets of HR. The average HR at baseline was $81.7 \pm 13.8 \mathrm{bpm}$. This was seen in spite of beta-blocker therapy in more than half $(53.3 \%)$ of the cohort. It was recognized that there were many factors to account for this deficiency.

Not infrequently, issues of drug related side-effects e.g. Lethargy, depression, erectile dysfunction, etc. hampered the prescription of optimal dosages of beta-blockers. Beta-blockers were also contraindicated/not encouraged in stable coronary artery disease patients who had certain co-morbidities e.g. Peripheral vascular disease, erectile dysfunction, bronchial asthma, etc. Patient non-adherence in relation to these side-effects and physician inertia were other equally important factors.

Addition of ivabradine effectively reduced resting HR that would translate to improvements in angina-related symptoms and other ischaemic parameters. The concerns with beta-blocker-related adverse effects were largely avoided with Ivabradine use. Ivabradine would be an ideal alternative when beta-blockers could not be used e.g. in patients with bronchial asthma. It had been shown to be as good as atenolol for HR-lowering and in fact, for each beat of HR reduction, it was more efficient in improving exercise duration on the treadmill [13].

In situations when beta-blockers were strongly indicated e.g. Postmyocardial infarction and left ventricular dysfunction, combination therapy with ivabradine offered an interesting choice for optimization of angina symptoms and HR lowering. The results from SHIFT study further consolidated the role of ivabradine in patients with heart failure with reductions in heart failure deaths and re-admissions for heart failure [14].

It was difficult to explain the paradoxical increase in the number of patients in Class III angina (note that there was a concomitant increase of the number of patients in Class I angina) after the $1^{\text {st }}$ month of therapy. This however reduced to a remarkably low level at the end of study, whilst the number of patients in Class I angina continued to increase. This observation contradicted the progressive reduction in the number of angina episodes and need of short-acting nitrate over the trial period. This might be a spurious result or reporting bias in a small sampled study.

The reduction of diastolic BP during follow-up could not be explained by pharmacological properties of ivabradine. Antihypertensive agent use (number of agents, dosage or combination therapy) was not recorded during follow-up. Such reporting bias could account for the unexpected finding.
The low incidences of side-effects in our cohort coupled to the high level of tolerance and acceptance of ivabradine amongst Malaysian patients dismissed concerns that this new agent might behave differently in an Asian population.

This study and other real world experiences with Ivabradine in the management of stable angina pectoris patients confirmed the findings of randomized controlled trials [15].

\section{Disclosure}

Authors reported no conflict of interest pertaining to this trial. This trial was conducted with the assistance of an unrestricted grant from Les Laboratoires Servier.

\section{References}

1. Elveback LR, Connolly DC, Melton LJ 3rd (1986) Coronary heart disease in residents of Rochester, Minnesota. VII. Incidence, 1950 through 1982. Mayo Clin Proc 61: 896-900.

2. Planning and Development Division, Health Facts 2008, Putrajaya, Ministry of Health Malaysia, May 2009.

3. DiFrancesco D (2006) Funny channels in the control of cardiac rhythm and mode of action of selective blockers. Pharmacol Res 53: 399-406.

4. DiFrancesco D, Camm JA (2004) Heart rate lowering by specific and selective I(f) current inhibition with ivabradine: a new therapeutic perspective in cardiovascular disease. Drugs 64: 1757-1765.

5. Fox K, Ford I, Steg PG, Tendera M, Ferrari R, et al. (2008) Ivabradine fo patients with stable coronary artery disease and left-ventricular systolic dysfunction (BEAUTIFUL): a randomised, double-blind, placebo-controlled trial. Lancet 372: 807-816.

6. Tardif JC, Ford I, Tendera M, Bourassa MG, Fox K, et al. (2005) Efficacy of ivabradine, a new selective I(f) inhibitor, compared with atenolol in patients with chronic stable angina. Eur Heart J 26: 2529-2536.

7. Tardif JC, Ponikowski P, Kahan T; ASSOCIATE Study Investigators (2009) Efficacy of the I(f) current inhibitor ivabradine in patients with chronic stable angina receiving beta-blocker therapy: a 4-month, randomized, placebocontrolled trial. Eur Heart J 30: 540-548.

8. Ferrari R, Cargnoni A, Ceconi C (2006) Anti-ischaemic effect of ivabradine. Pharmacol Res 53: 435-439.

9. López-Bescós L, Filipova S, Martos R (2007) Long-term safety and efficacy of ivabradine in patients with chronic stable angina. Cardiology 108: 387-96.

10. Ruzyllo W, Tendera M, Ford I, Fox KM (2007) Antianginal efficacy and safety of ivabradine compared with amlodipine in patients with stable effort angina pectoris: a 3-month randomised, double-blind, multicentre, noninferiority trial Drugs 67: 393-405

11. Fox K, Ford I, Steg PG, Tendera M, Robertson M, et al. (2009) Relationship between ivabradine treatment and cardiovascular outcomes in patients with stable coronary artery disease and left ventricular systolic dysfunction with limiting angina: a subgroup analysis of the randomized, controlled BEAUTIFUL trial. Eur Heart J 30: 2337-2345.

12. Campeau L (1976) Grading of angina pectoris. Circulation 54: 522-523.

13. Tardif JC (2008) Ivabradine: I(f) inhibition in the management of stable angina pectoris and other cardiovascular diseases. Drugs Today 44: 171-181.

14. Swedberg K, Komajda M, Böhm M, Borer JS, Ford I, et al. (2010) Ivabradine and outcomes in chronic heart failure (SHIFT): A randomised placebocontrolled study. Lancet 376: 875-85.

15. Köster R, Kaehler J, Meinertz T (2009) Treatment of stable angina pectoris by ivabradine in every day practice: The REDUCTION Study. Am Heart J 158 e51-e57. 